\title{
Entering into a community-university collaboration: Reflections from Feeding Laramie Valley
}

\section{FoodDignity}

\author{
Gayle M. Woodsum * \\ Action Resources International and Feeding Laramie Valley
}

Submitted July 9, 2018 / Published online July 18, 2018

Citation: Woodsum, G. M. (2018). Entering into a community-university collaboration: Reflections from Feeding Laramie Valley. Journal of A griculture, F ood Systems, and Community D evelopment, 8(Suppl. 1), 17-22. https:/ / doi.org/ 10.5304/ jafscd.2018.08A.017

Copyright @ 2018 by the Author. Published by the Lyson Center for Civic Agriculture and Food Systems. Open access under CC BY license.

T aving F eeding $L$ aramie $V$ alley become part of the

1 F ood D ignity research project was a unique opportunity to onntribute to a new body of knowledge associated with food systems work - to have the voices of the people of our community and our organization be heard. $\mathrm{N}$ ot just heard, but tak en seriously and emulated. A nd, because we would be part of a national collective of other communities, with the added benefit of being partnered with several highly regarded universities, our voices would tak e on a new identity- one of ex pertise in helping to define best practices for addressing local food insecurity.

That sounds good. Solid, confident, visionary. Small-town nonprofit does good, benefits from networking and collaboration. It's even kind of true.

But as is typical for a fledgling grassroots organization bent on accomplishing frontline social reform, the way we might publicly characterize our efforts doesn't always fall in line with the full reality

* Gayle M. Woodsum, President/ CEO, Action Resources International; community-university liaison, Food D ignity; founder, Feeding Laramie Valley; 968 North 9th Street; Laramie, WY 82072 USA; gayle@ actionresources.ngo of how we actually experience them. In the course of scrambling for support and recognition, community-based organizations learn what language to use, what partnerships to foster, and most importantly what narratives to put forth in representing our missions. It's how we crack open doors to institutions and power brokers capable of backing us- and legitimizing our work. It's how we manage to gradually then steadily tap into streams of funding that will not only grow, but become consistent and sustainable. Refining the presentation of our activism is how we survive.

How we learn to survive, however, can also be the means through which we sometimes lose our way. This is especially true when the paths we take involve building purported partnerships with entities that possess greater financial backing, more persuasive power, and more of a standard default position of universally recognized expertise than

\section{Funding Disclosure}

Food Dignity (http:/ / www.fooddignity.org) was funded by U.S. D epartment of Agriculture-National Institute of Food and Agriculture's Agriculture and Food Research Initiative Competitive Grant no. 2011-68004-30074. 
what we have. This kind of inherently inequitable stance in the world means that attaining true partnership is going to be at the very least a formidable challenge, and quite realistically may be impossible to achieve.

In the spring of 2010, a project promising multiple community-university partnerships and involvement in community-based participatory research (CBPR) was what landed at my feet through the proposed Food Dignity research project. I heard myself saying "yes" before I really understood what I was agreeing to. I stand by the words I used to open this essay. But they're the words of a community organizer who understands the value in presenting oneself like a team playeran amiable and eager-to-please team player, if at all possible. Offering up more of the truth, or a slightly different angle on the truth, has the potential to put all the players at risk. It also has the potential to upgrade the level of rigor attached to CBPR and the level of importance to be derived from its findings.

Therefore, I'm going to begin the story of Feeding Laramie Valley signing on as part of the Food Dignity project again.

Christine Porter made a cold call to me in the late winter of 2010. Or maybe it was lukewarm in the sense that, the way I heard her tell it, she'd made other calls to people in Laramie, Wyoming, who were said to be involved in community food systems work, and when she told them what she was looking for, they told her she needed to call me.

The first time Christine spoke to me about the Food D ignity research project, it was just an idea, an application in process. Community food systems research composed of five communities across the country, for five years, with five million dollars in funding. Laramie wasn't a random choice for Christine. She was finishing up her doctoral work at Cornell University, had accepted a position at the University of Wyoming, and figured it made sense to include Laramie as one of the proposed communities for the project she envisioned. I remember feeling pleased to be called that first time, and polite about the enthusiasm I heard in this young stranger's voice who dared to believe she could make a successful bid for the first major grant she would ever write, with just six awards being offered across the nation.

Beyond that, I didn't think much about it all. I was an absolute neophyte in the budding world of community food systems work. To me, food systems work meant organizing a day-long workshop on gardening here in Laramie, in a highelevation, 56-day growing season; helping to organize and build a community garden in one of Laramie's lovely parks; bringing in a greenhouse and producing fresh vegetables to serve at the local senior center I was directing; and mostly finding other people in Laramie for whom the concept of local food was a high passion, and who could teach me about what that meant in larger, yet practical, everyday terms.

The next time I heard from Christine, a few weeks had passed and my world had flipped. I was unemployed, newly single, and perched in temporary housing. Christine Porter was deep into the massive pile of requirements that accompany a federal grant application, so I quickly jumped into "things are kind of different from the last time we spoke, but everything's great" mode. I figured if she was confident about her ideas for tracking community-based efforts to reduce food insecurity, I could be happy to do my part. I may have been cut loose from life as I'd known it, but I was able to reassure Christine about the viability of the food systems work I'd started: I was working with a coalition of people installing a garden in a city park, and three of us were getting ready to launch a food rescue and distribution project at Laramie's farmers market.

And, by the way, my long-time nonprofit organization, Action Resources International, had 501(c)(3) status and a DUNS number in good standing. Which meant, in what I believed to be the unlikely event this research grant was awarded, the Feeding Laramie Valley project I was trying to hang onto would be legally capable of subcontracting as one of the Food Dignity project community sites. Seeing how I was kind of desperately in need of paid work at that point in time, was committed to not letting Feeding Laramie Valley (FLV) die young, and learned that Christine's proposal included a little bit of funding for staff and project support at community sites, I agreed to review 
drafts of the overall grant as well as draft a scope of work for FLV.

While the formal concept of community food systems work was new to me, community organizing for social justice was not. I'd been fostering constituent-led activism for a variety of causes since the early 1980s, always from a grassroots platform and always from scratch. I'd never gotten over the notion that leaping into thin air on behalf of lost causes and unheard voices was well worth doing, mostly because my own adult life seemed to have been launched from such a wellspring. After living and working from this perspective for nearly 30 years, I'd managed to add some skills to the mix - as well as a heavy dose of the reality involved in making a lifetime commitment to social activism.

So when Christine Porter called, in the fall of 2010, to say that she and the University of Wyoming, in fact, had been awarded one of the few U.S. D epartment of Agriculture-National Institute of Food and Agriculture (USD A-NIFA) research grants, I received the news with a mixed reaction of emotion and strategic planning. For the most part, the money (in the form of the community support package provided to each community site) would be Feeding Laramie Valley's first award of funds that would cover a five-year span of time, and included money for personnel. This isn't the kind of thing that typically happens in a grassroots startup. The vast majority of nonprofit funding sources prefer to support well-established programs with fully backed infrastructure already in place. When they do provide program funding, salaries are rarely included as allowable expenses.

Like me, Feeding Laramie Valley was bursting with activity and vision but hanging on by a financial thread. Suddenly (if the project, its community volunteers, and I could survive another six months or so) I was facing the promise of five years of a basic funding stream that would help support projects underway, a small part-time salary for me, plus part-time wage support and minigrant support for community members. Feeding Laramie Valley was also about to claim a place as part of a national, community-led food systems movement. This constituted a windfall, for which gratitude bubbled in my veins.
But even as I absorbed the hopes being raised for FLV, and while I was deeply sincere in offering well-deserved congratulations to Christine Porter for landing the grant, my decades of experience with the reality of change-the-world efforts created more of a quiet but definite grating sensation at the back of my brain. We hadn't won the lottery. We'd signed on for a research project that carried with it a long list of requirements (or, as we would come to know them, deliverables), all associated with research under the auspices of several universities and their academic cohorts. In spite of the grant application's liberal use of verbiage referencing social justice tenets of various sorts, the bottom line was that I was signing Feeding Laramie Valley, myself, and a bunch of other community folk into an alliance not of our making, and one harboring a history not known for its respect of communitybased knowledge as being equal to what's generated in the academy.

My education in social activism came from the streets of desperate need to see fundamental change happen in the world. My teachers were childhood oppression and violence, followed by the formidable mentoring of women who created the first organized network of safe houses for victims of domestic violence, launched the Take Back the Night movement, offered up lesbian separatism as a fountain of respite care, and pummeled hard against the ignorance of my white-skinned, heteropassing, class-privileged packaging.

By the time the Food Dignity project invited me to be part of its enterprise, I was chock-full of what my friend Lina D unning says is being a woman who knows too much. Which is why, when I began to sign on the contractual dotted lines in so-called partnership with the University of Wyoming and a web of extraordinarily diverse people and agendas in the name of food justice, there was an internal voice nagging at me. The voice would say, "Y ou know better than to do this."

It seemed like a reasonable assumption that a study on the growing and distributing of healthy food across five disparate communities would be relatively angst-free. I also clung to the hope that something we'd had only a small part in creating was going to provide opportunities that enhanced rather than burdened our young organization. I 
signed that first contract, quickly began to fashion the kind of public statement about the decision, which ended up sounding much like my opening paragraph for this essay, and dove in head first.

Seven years later, it's not possible to overstate the impact the Food Dignity research project had on Feeding Laramie Valley, the communities of Laramie and Albany County in Wyoming, and on me- both personally and professionally. The best of what I'd hoped for and the worst of what I'd feared rolled out in a demanding stretch of time that challenged everyone involved. Much of it sorted itself into predictable categories.

The fact that this was a research project provided a context for FLV that was unusual for an organization just beginning to define and claim space for itself. The mandate to record and reflect on every aspect of our work- in far more depth and with greater discipline than classic grant reporting - helped staff and volunteers take a more serious look at what was being accomplished, while paying greater attention to the details of every element in each project. Community gardening wasn't just about the number of plots, the signed agreements, and whether or not the rules were being followed. Being part of the Food Dignity project created added layers of looking at the details behind what gardeners were choosing to plant and why; how soil health, watering practices, and companion planting increased yield; and how plot stewards came to learn about them. Beyond that, the design of the Food Dignity research component encouraged FLV to capture photographs and interviews with community and backyard gardeners as well as small local farmers. These explored community-based perspectives, experiences, and vision for how growing one's own food influences food access, food security, and a personal sense of food sovereignty. Because staff, community advisory board members, and participants connected to Feeding Laramie Valley were motivated and encouraged by its community-driven mission, and because FLV as an operating unit took the Food Dignity project's grant narrative to mean that community language, knowledge, and experience was highly respected and valued, this ongoing baseline for the project was a positive one.

As the Food Dignity project came to life, however, the potential pitfalls I'd feared at the start began to emerge as actual bumps in the road; although it would, perhaps, be more accurate to call them bone-jarring potholes. A major cause was the scope and sheer magnitude of cross-country involvement between deeply passionate community organizers and intensely committed academics. The harsh reality of this vulnerability in the plan was first revealed during the first of six national allteam meetings built into the project. It was there, and at every subsequent meeting, that both language and voice rose to the surface and emphasized the chasm between the Food D ignity community leaders and its academic team members (as well as among them). The diversity in geographic location, race, ethnicity, gender, lifestyle, and experience among the community-based social activists stood in stark contrast to the all-white group of researchers with academic standing and leadership roles in defining and delivering supremely rigorous research results.

Putting face and voice to the extraordinarily disparate group Christine had assembled threw an instantaneous spotlight on contradictions intrinsic to how the Food Dignity project was likely to play out. With an emphasis on gathering community knowledge and narratives related to multiple project interests (food production, minigrant programs, photo essays), the project proposal itself suggested a unique approach to standardized research practices and goals, even for the less structured approach of community-based participatory action research.

The level of experience and expertise in the fields of community organizing, sustainable food security, and social justice among the community leaders stood toe-to-toe with the level of expertise held by members of the academic team in their own specialty fields. But there was nothing in place from an original design standpoint that sought to bridge the gap between the accustomed standards and procedures of academic-led research and the realities of community-led, frontline activism dedicated to social change. By partnering highly regarded, cutting-edge fields of study, organizations, and individuals without a strategic plan for analyzing and then bridging the fundamental differences between them, it was predictable that 
each would be inclined to cleave to its own familiar process for managing perceived and real power differentials. This made for rough going when communication inevitably slid into separate camps of perspectives between the studier and the studied, management and the managed.

Nevertheless, the same intensity of position and perspective that caused internal conflict throughout the span and work of the Food Dignity research project also created some truly unusual and meaningful outcomes that really ould be described as collaborative and in the spirit of partnership.

Feeding Laramie Valley, based in the same community that housed the university that received the Food Dignity project grant and employed its director, was given the opportunity to serve in a lead role on projects that included:

- distribution and support of US\$30,000 in minigrants to community food projects over several years;

- production, publication, and two public receptions for displays of a series of photos, narratives, and videos capturing historic and innovative community food systems accomplishments;

- a four-year study on backyard and community garden yields in a high elevation, Zone 3-4 region;

- development and implementation of a paid summer educational internship program in food systems work, including food production and distribution based on a local food sovereignty model; and

- convening and facilitation of a joint community-academic advisory group for the development of a food systems track for a sustainability minor at the University of Wyoming.

Dozens of people in Albany County became involved with community food systems work through projects that were funded at least in part by the Food Dignity project. Although much of the work was piecemeal and temporary, FLV would ultimately be able to leverage those start-up opportunities into what has become a robust and growing employment base. Two of FLV's team members on the Food Dignity project now have full-time, management-level staff positions with the organization.

Feeding Laramie Valley's value and recognition in the community were definitely enhanced by being involved with the Food Dignity project. It was also challenged by its association with the university's connection to the project, which sometimes led to the university being credited with the existence and accomplishments of the community organization.

There's no doubt that what the Food Dignity project brought to Feeding Laramie Valley in national and even international exposure to opportunities for leaming and presenting would not have occurred as quickly nor to such an extent without that connection. The personal and professional relationships developed between FLV and the project's four other community sites were, and continue to be, extraordinarily meaningful.

I'm always entertained by how we can look back over any stretch of time in life and think, "Wow, look how young we were!", even when we weren't young at all when standing at that particular starting gate. I was 55 years old when the Food Dignity research grant began in 2011. I stepped into the embrace of that one-of-a-kind, complicated project with my own complex mix of skepticism and hope, dragging an entire organization and a big chunk of a community along with me. There was nothing clean or straightforward about my choice to take the step, and the seven years following that decision went in directions I never anticipated.

Ultimately, the framework envisioned by Christine Porter held true. It enabled a breadth of learning and accomplishment to take place that could not possibly have been imagined at the start, nor within the pages of the formal proposal. The strictures and ignorance unavoidably embedded within the list of grant deliverables were countered by the unparalleled mix of brilliance, courage, creativity, and stubborn belief in the ability to make substantial change in the world that came with the people who made up the Food Dignity project team over the years. It was almost as if whatever trials and tribulations came to life as a result of the 
flawed aspects of the project were precisely what shed light on a better, alternate path. There was enough flexibility built into the project that some of those alternate paths could be successfully undertaken and added to the body of work.

As for the alternatives that were needed but would never be served by the project's scope or goals, time is already seeing some of them emerge in subsequent community-based efforts. For example, Action Resources International has taken the seed of collaborative pathway modeling planted within the Food D ignity project and has begun to utilize it as a unique tool for community-based and -led collaboration research, development, implementation, and evaluation. Feeding Laramie Valley is serving as a statewide AmeriCorps VISTA program through which VISTA members work full time to assist with sustainable capacity-building for emerging grassroots social change efforts. The organization has joined forces with groups across Wyoming to begin development on multiple food hub sites.

If the Food Dignity research project ended up accomplishing anything at all, it succeeded in providing a five-year opportunity for a diverse array of activists, scholars, and students to dig at, uncover, and radically challenge both the notion and reality of truth-saying on topics that extend beyond its surface mainstay of communitygenerated responses to food insecurity.

I made the decision to have Feeding Laramie Valley join the Food D ignity research project because we needed the money, and in the back of my mind I thought it might provide a helpful boost to our understanding of what community food security, sovereignty, and sustainability could mean. As a result, I was catapulted into an entire world of people investing the very best of who they are, in service to understanding the truth of the way in which equity, justice, and access are kept out of reach, and to help create the means to not only remove barriers but to change the landscape on which lives are built. I may not have known this was the gathering that Feeding Laramie Valley was being invited to, but I'll never lose sight of the honor it ended up bestowing on all of us as a result of being part of it. 